\title{
DE HOMBRES DEL REINO A REPÚBLICA DE HOMBRES. COLECTIVIZACIÓN, COMUNIDAD Y PODER EN HARRINGTON Y BABEUF
}

\author{
From men of the kingdom to a republic of men. \\ Collectivization, community and power in Harrington and \\ Babeuf
}

\author{
Luis Sánchez Quiñones \\ Abogado \\ luissanchezquinones@hotmail.com \\ http://dx.doi.org/10.18543/ed-68(2)-2020pp293-321 \\ Recibido: 05.12.2020 \\ Aceptado: 21.12.2020
}

\section{Resumen}

El pensamiento utópico ha sido una constante en la formulación de los movimientos políticos así como en la configuración de los derechos individuales. Las revoluciones de los siglos XVII y XVIII ofrecieron notables ejemplos de sociedades articuladas a través de ideas elevadas en las que la redistribución de la riqueza y una mayor participación política eran signo común. Sin embargo, esas aparentes coincidencias escondían diferencias de planteamiento y de concepción, como exponemos en el análisis de las ideas de James Harrington y Gracchus Babeuf.

\section{Palabras Clave}

Sociedad, propiedad, religión y colectividad.

\section{Abstract}

Utopian thinking has been a constant in the formulation of political movements as well as in the shaping of individual rights. The revolutions of the seventeenth and eighteenth centuries offered notable examples of societies articulated through lofty 
ideas in which the redistribution of wealth and greater political participation were a common sign. However, these apparent coincidences concealed differences in approach and conception, as we show in the analysis of the ideas of James Harrington and Gracchus Babeuf.

\section{Keywords}

Society, property, religion and community. 
Sumario: I. INTRODUCCión. II. LA RepúBliCA DE OCEANA. DigGERS, COMMONWEALTH Y SIÓN. 1. Diggers y Winstanley. 2. Harrington y el republicanismo religioso. III. EL RESURGIMIENTO DE LA SOBERANÍA POPULAR. MORELLY, CATASTRO, ACCIÓN POLÍTICA Y EL TRIBUNO DE LA Plebe. IV. Hombres del Reino. República de hombres. V. PropieDAD: ESClAVITUd Y PODER. VI. CONCLUSIONES. BibliogRAFIA.

\section{INTRODUCCIÓN}

El carácter utópico de las formas de gobierno ha sido objeto de constante formulación a lo largo de la historia. Sin embargo entre los siglos XVII y XIX el interés por configurar la estructura de gobierno lo más perfecta posible, despertó un interés inusitado al amparo de los distintos procesos políticos y revolucionarios que se fueron sucediendo.

Inglaterra y Francia no fueron ajenas a dichos experimentos. Dos de los principales exponentes de dichos intentos los encontramos en las obras de James Harrington y Gracchus Babeuf que bosquejaron dos formas de gobierno que aspiraban a una mayor participación del individuo en la acción legislativa en el marco de una república de corte popular. Sin embargo, esa participación popular que desarrollaron ambos no fue idéntica, escindiéndose en dos líneas diferentes: una república agraria y popular de corte liberal con fuerte influencia religiosa y que excluía a la monarquía bajo el prisma de Harrington y una república popular y colectivista en el caso de Babeuf que ha sido considerada por muchos autores (Maillard 1994, 93-96) ${ }^{1}$ como precursora del comunismo (Harkins, 1990-1991, 433)2.

Abordaremos aquí las líneas generales de esas formas de gobierno y la incidencia que el pensamiento de Harrington tuvo sobre el de Babeuf, así como la posible vigencia que ambas estructuras políticas tendrían en el día de hoy.

\footnotetext{
${ }^{1}$ Algunos autores fechan el nacimiento del comunismo en París a partir del año 1830, enlazando la publicación del libro de Buonarroti La Conjura de los Iguales en el que hablaba de su experiencia personal vivida con Babeuf y las posteriores revoluciones que tendrían lugar a partir de ese mismo año. Esa rehabilitación sirvió para que a partir de 1840 se identificase plenamente el pensamiento de Babeuf con los incipientes movimientos comunistas que se produjeron a partir de esa fecha.

2 A día de hoy algunos autores mantienen que hasta 1786 Babeuf no era un pensador estrictamente socialista ya que todavía no había dado una solución en tales términos ideológicos al problema de la propiedad.
} 


\section{LA REPÚBLICA DE OCEANA. DIGGERS, COMMONWEALTH Y SIÓN}

La Guerra Civil inglesa fue el contexto en el que se fraguó el pensamiento de Harrington. Como es sabido, este período concluyo con la decapitación de Carlos I y el inicio del Protectorado cromwelliano (Guizot 1985, 232). Su pensamiento puede considerarse como el resultado de una tensión que fue en aumento desde el inicio del reinado del monarca Estuardo quien careció de la cintura política y el poder de sus antecesores, Enrique VIII e Isabel I.

Lo que habían sido sendos reinados en los que el Parlamento había permanecido adormecido ante el poder de la Corona (McGurk 1999, 91) se tornó en un enfrentamiento directo entre los parlamentarios y el monarca, arrancando los primeros - poco a poco- concesiones y prebendas del monarca hasta el punto de lograr derribarle. Recordemos que durante el reinado de Carlos I se había otorgado la Petition of Rights de 1628, la cual ya fue redactada en términos de denuncia contra el poder real, al que se acusaba de imponer exacciones injustas y vulnerar los antiguos derechos y libertades contenidos en la Carta Magna.

Eran tiempos en los que la monarquía inglesa había visto cómo su prestigio decaía notablemente. Caída que fue en aumento durante el posterior enfrentamiento civil (Good Old Cause) y que fue sustituida por la República que apenas duró unos años. En este escenario se cuestionó abiertamente la figura del monarca y de la propia Iglesia de Inglaterra, la cual había permanecido muy vinculada a la Corona. Los movimientos puritanos, ranters, cuáqueros, levellers -autores del célebre Agreement of the People- y diggers, ganaron peso e importancia, proponiendo alternativas políticas más o menos sólidas o afortunadas al establishment existente.

\section{Diggers y Winstanley}

Estos espacios permitieron que las ideas de tales grupos gozaran de mayor publicidad que intentos precedentes, como aconteció con los diggers (Bowman 2005, 398-399) (cavadores o labradores). La principal referencia de los cavadores era Gerrard Winstanley quien formuló -como hiciera un siglo antes Tomás Moro (Moro 1977, 58-60) ${ }^{3}$ - una suerte de sociedad utópica basada en la rectitud que debía derogar un sistema en el que pocos

${ }^{3}$ La organización política de la república de Utopía se sustentaba sobre magistrados denominados sifograntes elegidos cada uno de ellos por grupos de treinta familias. Los sifograntes elegían a su vez a los traniboros que a su vez elegían al príncipe que podía ser depuesto en caso de tiranía. Se caracterizaba además por la tolerancia religiosa, por el rechazo a la guerra y un valor cuidadosamente medido de la riqueza, despreciando la ostentación y el lujo. 
vivían del trabajo de muchos a través de una redistribución estricta de la riqueza controlada por el Parlamento. Esa reorganización económica se regía por una aplicación estricta de las Escrituras ya que si bien Winstanley reconoció la tradicional importancia de la propiedad en la sociedad anglosajona (Attenborough 1922, 99-119) ${ }^{4}$, criticaba la falta de un reparto equitativo de la misma, convirtiéndola por tanto, en el origen de todo mal, como veremos a continuación.

La «culpa» de dicha situación era de la monarquía la cual debía ser suprimida al tratarse de una forma intrínseca de maldad que solo buscaba su propio bien (Bowman 2005, 400-401), postulando un sistema anual de jueces que limitase las posibilidades que pudieran ser corrompidos. Planteaba una construcción política que sublimaba el poder divino y que supeditaba el poder terrenal (Winstanley 1941a, 130-131), convirtiendo la libertad en la capacidad para poder hacer lo que el hombre quisiera sin restricciones, no pudiendo ser sometido al poder de ningún terrateniente (Winstanley 1941b, 597), admitiéndose únicamente la esclavitud de forma excepcional como condena por la comisión de un delito.

Winstanley desgajó la condición del hombre de la propiedad. Consideró que la propiedad es el nacimiento de las penurias del hombre y de los conflictos existentes, puesto que aquellos que no tienen propiedades se ven abocados al crimen y robo (Winstanley 1941c, 200-201). Afirmaba que el hombre no propietario era objeto de explotación por parte de aquellos que sí lo eran, quienes abusaban de su posición contratando los servicios de los hombres desposeídos a cambio de magros salarios, reservándose para sí los beneficios de su trabajo (Winstanley 1941d, 258-259). El planteamiento de Winstanley - pese a aceptar la existencia de la propiedad- constituía un ataque directo al carácter cuasi sagrado que tenía la misma en la Inglaterra de mediados del siglo XVII. Carácter éste que hundía sus raíces en la herencia sajona y normanda preexistente.

Destruido el concepto de «tuyo o mío», Winstanley apostó por atribuir la tierra de forma común -incluyendo sus recursos naturales- compartiéndola todos los habitantes por disponerlo así las leyes de la creación (Winstanley 1941b, 519-520). A tal fin se debían crear graneros y almacenes comunes para depositar el fruto del trabajo de las distintas comunidades, así como los excedentes obtenidos a través del trabajo realizado de forma particular con el fin de adquirir o intercambiar bienes allí depositados (Winstanley 1941b, 583-585). Afirmó igualmente que Inglaterra no podía ser una comunidad libre hasta que los hombres en general -y los diggers en concreto-no tuvieran derecho a cultivar y labrar su propio terreno de la misma forma que los

${ }^{4}$ Ya se contemplaban reglas precisas para su atribución y litigios en las leyes sajonas. 
grandes propietarios (Winstanley 1941d, 260-261). La propiedad común así constituida se denominaría commonwealth, rigiéndose por los oficiales y las leyes.

Nos hallamos ante una forma de colectivización de la propiedad que ponía fin al conflicto entre los hombres (Rowland 2014, 79-80). Pero esto no resultaba suficiente. Debían desterrarse las leyes existentes y aplicar las procedentes del reino de Jerusalén, es decir, la ley divina (Winstanley 1941d, 249-251). La ley vigente no era aceptable al haber sido otorgada por los antiguos reyes y resultar además, arbitraria. La nueva ley debía acordarse en su adecuada medida para cada ocasión, siendo ésta exigencia la de un gobierno justo (Winstanley 1941b, 528-529). Mediante este cambio, la commonwealth se convertiría así en la forma de gobierno que liberaría a los hombres, dejando de estar sometidos de la voluntad de un solo hombre para regirse por la ley de Dios (Winstanley 1941b, 534-535) -cuyo origen se encontraría en Adán- siendo su fin último obtener, a través de la voluntad del pueblo, la preservación común -entendida como buscar el bien de los demás-, la paz y la libertad. Obviar ese bien común no era opción, puesto que en esa elusión nacía la tiranía que era la causante de todos males (Winstanley 1941b, 537538).

A la idea de preservación común añadía la preocupación de que las leyes pudieran resultas justas, fijando -vrgr.- una serie de garantías básicas en el proceso -inexistentes a su juicio-que incluían que la acusación fuera pública y se sustentase en al menos dos testigos, prohibiéndose la tortura (Winstanley 1941b, 590-591). Winstanley, equiparaba la situación del hombre con el mito de la serpiente bíblica. Un conflicto entre rectitud y carne en el que las diversas facciones de hombres peleaban como grupos de perros (Rowland 2014, 79-80).

No obstante y pese a esa referencia directa al orden divino y a una concepción estrictamente religiosa, atacó duramente a la Iglesia de Inglaterra (Winstanley 1941b, 504-505) por entender que había servido de forma indistinta al Papa, al protestantismo y a cualquiera que la hubiera respetado sus privilegios (Winstanley 1941e, 358-359). Identificaba en ese momento a la Iglesia de Inglaterra con el poder (Webb 2003, 591). Y al poder con la monarquía, por lo que debía desaparecer. La nueva sociedad excluye a los clérigos que únicamente perciben diezmos (Alsop 1994, 15-18) y a los señores que dirigen a hombres de espíritu ciego (Winstanley 1941b, 522-523) que ignoran la necesidad de modificar esa situación.

Propuso en consecuencia que el gobierno se compusiera de leyes correctamente ejecutadas y oficiales. Una estructura social -que eliminaba las trabas impuestas sobre los derechos de nacimiento de los hombres así como la esclavitud (salvo en caso de que mediase condena) - con el fin de lograr la común preservación como objetivo último de la commonwealth. Los padres 
de familia asumían la condición de oficiales de la commonwealth -dentro de su obligación de enseñar y velar por la paz-y las shires debían elegir sus propios overseers, encargados de velar por el orden y la paz. Los cargos eran electivos y nunca impuestos, puesto que la imposición se identificaba con la forma de actuar de la monarquía (Winstanley 1941b, 539). Los requisitos para dicha elección -de carácter anual-incluían contar con más de 40 años, haber perdido sus tierras o haber padecido persecución de la corona (Winstanley 1941b, 543-544).

Los oficiales se dividían según el ámbito de adscripción -parroquia, condado, ciudad o nación- en diversas figuras que incluían padres o maestros de familia -encargado de instruir a los hijos-, peace-maker-suerte de policía-, overseer compuesto de varios grados (desde asistente del peace-maker y con unas funciones similares al sheriff, a asesor de las familias en materia de comercio, encargado de distribución de los bienes comunes y en su rango más alto, anciano de más de sesenta años) vigilar el mantenimiento de la pazsoldados, task-master (que era una suerte de ejecutor de sentencias), verdugo y jueces (Winstanley 1941b, 544-556).

El Parlamento fue configurado como una corte suprema de equidad que vigilaba la labor de todos los oficiales del reino y que representaba a toda la commonwealth. Sus funciones básicas eran cuatro: supervisar la labor de los oficiales, abolir las viejas leyes y costumbres y dictar unas nuevas que respetasen la libertad de los hombres, previa consulta al pueblo de las mismas y como remedo excepcional, en caso de guerra poner los medios necesarios para defender la paz común, incluso si fuera necesario alzando un ejército (Winstanley 1941b, 556-561).

Podemos afirmar que removió los cimientos de la sociedad inglesa de la época, creando una conciencia de clase que partía de una reorientación del concepto de propiedad y de la abolición del sistema de gobierno preestablecido (Webb 2003, 592). Esa concepción le conducía igualmente a rechazar los efectos del gobierno monárquico y en concreto, el sistema de enjuiciamiento y condenas que regía en la época por considerar que el único sistema de castigo válido era el trabajo en la tierra vistiendo las ropas que evidenciasen la condición de infractor (Rogers 1996, 741). Esto no impedía que el complejo sistema administrativo que propuso tuviera como objetivo que se cumpliera y conociera la ley como medio para prevenir los abusos y para implantar la reforma legal que auspiciaba (Rogers 1996, 742).

\section{Harrington y el republicanismo religioso}

El pensamiento de Harrington tuvo presente muchas de las cuestiones ya anticipadas por el pensador digger. No se trata sin embargo de una traslación mimética. Harrington se desliga parcialmente del carácter eminentemente 
religioso que trasluce del pensamiento digger para incorporar una sociedad -que si bien parte de un esquema común- que no renuncia a la propiedad y que aunque se muestra fervorosamente republicana, no niega rotundamente la posibilidad de convertirse en una monarquía controlada por el Parlamento.

Oceana no es sino un trasunto de la República Inglesa puritana que impuso Cromwell ${ }^{5}$. Una sociedad fuertemente militarizada, fervorosamente creyente sin alcanzar el cénit de Winstanley y sujeta a unos estrictos cimientos anclados en la Cámara de los Comunes que era, la que en definitiva, había derrocado, enjuiciado y condenado a muerte al monarca, pero que incluso una vez ejecutado el rey, reprodujo legislativamente las estructuras correspondientes al sistema político fenecido ${ }^{6}$ (Gardiner 1906, 405-417), equiparando al propio Cromwell como una suerte de príncipe (Smith 1999, 51-52).

Una sociedad unida bajo un Dios -el de los puritanos- que menospreciaba a otras confesiones a pesar de los esfuerzos de Cromwell de transmitir cierta tolerancia y regida por un poder ejecutivo mixto -militar y políticoconcentrado en la persona del Lord Protector que era el propio Cromwell y apoyado sin ambages por el ejército al que él mismo había pertenecido y que era dirigido por sus antiguos compañeros de armas (Fitzgibbons 2013, 10011103). Una sociedad que denostaba por igual a levellers, ranters, diggers y cuáqueros. Su nombre -commonwealth (bien común)- la convertía, a ojos de sus ciudadanos, en el adalid de las libertades y del auténtico Dios protestante frente a las monarquías enemigas, sobre todo, las católicas (Barnard 1997, 37).

Estos caracteres se advierten en Oceana, la cual era descrita por Harrington como «la más bendita y afortunada de las naciones» (Harrington 1977a, 157). Una sociedad regida por el imperio de la ley y no de los hombres cuya raíz era el interés preponderante del colectivo que era a su vez, la ley de la naturaleza (Harrington 1977a, 171). Tal interés desemboca en el gobierno civil de los hombres (Harrington 1977a, 172). La commonwealth era igualitaria ya que el gobierno se estableció sobre una distribución igualitaria de la tierra y una rotación en el poder compuesto de tres órdenes: el senado debatiendo y proponiendo, el pueblo resolviendo y los magistrados ejecutando, siendo elegidos de forma rotatoria mediante sufragio (Harrington 1977a, 181). Un carácter eminentemente legal frente a la monarquía que era un gobierno de pocos hombres y no leyes (Harrington 1977b, 401-403), ya que en ésta última la ley procede de la exclusiva voluntad del monarca, voluntad que se extiende a la unión de los territorios que formaban su imperio (Harrington 1977b, 410-413). Ensalzó igualmente el papel de la commonwealth,

${ }^{5}$ El propio libro está dedicado a Cromwell, rogándole que hiciera por Inglaterra lo que Licurgo hizo por Esparta.

${ }^{6}$ En alusión al Instrument of Government. 
cuyo gobierno no puede ser sedicioso salvo que medie alguna desigualdad en su creación particular (Harrington 1977b, 431).

Para Harrington el senado y el pueblo son el poder legislativo y los magistrados el poder ejecutivo, sometiéndose a leyes eclesiásticas y civiles. La simbiosis entre religión y estado es evidente ya que la commonwealth acoge la conciencia nacional. No cabe aceptar una conciencia privada puesto que aquella produce la religión particular de cada hombre. Solo la convicción nacional produce una religión nacional, tal y como sucedía en Israel (Harrington 1977a, 185) delimitando a través de la religión el poder civil, basado en unas pocas leyes que solo pueden ser reformadas de forma excepcional. Petrificó así la voluntad del conjunto de la sociedad, salvo que el gobierno no fuera bueno, pues un mal árbol no puede dar buen fruto (Harrington 1977a, 187).

No obviaba el autor inglés la necesidad de otorgar a Oceana un origen mítico ${ }^{7}$. Su constitución (Harrington 1977a, 191) era una sucesión de los pueblos que la habían gobernado: romanos, teutones, escandinavos y francos. Los primeros consideraron Oceana como una provincia, los segundos como una monarquía y los últimos como un feudo dirigido por los ealdormen (Harrington 1977a, 192). Los francos (neustrians) dividieron el reino en feudos poniendo al frente a los earls, barones, división nobiliaria que Harrington consideraba necesaria para que hubiera igualdad de poder, excluyendo de dicha igualdad a la monarquía, a la que advirtió que si gobernaba con el apoyo de las cámaras no tendría que preocuparse por su trono aunque tuviera que guardar cierta prudencia, mientras que si gobernaba apoyada exclusivamente en nobleza y clero no lo mantendría durante mucho tiempo (Harrington 1977b, 450-451). Rechazó en todo caso la monarquía, salvo que se tornase en una monarquía popular equilibrada (Harrington 1977c, 376) a semejanza de la habida en el reino de Israel.

Esa limitación al poder real -de difícil asunción en los años en los que Harrington escribió Oceana ${ }^{8}$ - permite afirmar la condición de reproducción que tenía Oceana de la sociedad inglesa del Protectorado (Harrington 1977d, 401-403). Su negativa a aceptar la monarquía o al menos una monarquía como la recientemente destronada, se complementa con la inclusión en los estamentos de su República ideal de los lores espirituales y temporales divididos estos últimos entre realistas y commonwealtshmen (comunes) (Harrington 1977a, 203). Los lores realistas estaban excluidos del consejo de gobierno -del que también se expulsa a la realeza, como acontecía en la

${ }^{7}$ Obsesión que se reproduciría en los siglos siguientes en Inglaterra con la constitución mixta.

${ }^{8}$ Carlos I negó autoridad a sus jueces para condenarles al entender que estaba por encima de ellos. 
República Inglesa en la que se inspira- eligiéndose a los parlamentarios por el pueblo bajo la dirección de Lord Archon, único legislador de Oceana, quien estaba rodeado de un consejo de 50 personas que le asistían (Harrington $1977 \mathrm{a}, 207)$ y que eran conocidos por su sabiduría y prudencia.

El denominado consejo de legisladores forma parte del modelo político de Oceana en el que la esencia es el pueblo dividido en función de la calidad, edad, salud, y lugar de residencia. La calidad dividía al pueblo en hombres libres- ciudadanos y sirvientes (que quedaban apartados de la participación en el gobierno) (Harrington 1977a, 212), la edad separaba a los guerreros de los que no lo eran, teniendo además los propietarios de más de cien libras en dinero o bienes la obligación de ser soldados de caballería y el resto a pie, conforme a la usanza de la antigua Roma (Harrington 1977a, 213), siendo la pertenencia al orden ecuestre una muestra de las obligaciones públicas del sujeto y no causa de división social, evitando así crear una causa de destrucción de la sociedad como ocurrió en la propia Roma (Harrington 1977a, 216).

Por cada región propuso que se designasen dos supervisores que instruyesen sobre las fórmulas de elección, designando los elegidos un justicia de paz, un jurado, un capitán y un constable (policía) entre ellos, elección que se sometería a los censores (Harrington 1977a, 222-223). Limitó la posesión de la tierra cuando la misma excediera de cinco mil libras, obligándose a su división, no permitiéndose la tenencia de propiedades por encima del valor de 2000 libras las cuales además no podían acumularse por sus titulares (Harrington 1977a, 231). Tampoco podían heredarse bienes por valor superior a 1500 libras, rigiéndose la nación por una ley agraria que pretendía evitar la excesiva acumulación de poder.

Cada tribu ostentaba una prerrogativa que incluía el poder judicial y legislativo. El primero incluía una votación secreta que podía ser afirmativa, negativa y en blanco (non-sincere), siendo esta prerrogativa el órgano judicial supremo y último de la Commonwealth (Harrington 1977a, 281-283). El exceso del gasto público debía ser empleado para reparar los daños de la guerra y para el mantenimiento de los cargos públicos (Harrington 1977a, 287), garantizándose el derecho a la educación ${ }^{9}$ creando escuelas públicas en cada tribu en proporción correspondiente a la población (Harrington 1977a, 300302) así como un ejército popular ${ }^{10}$. El poder soberano permitía -a través de una elección igual o rotación- elegir las distintas ramas que componían el mismo (Harrington 1977a, 333-337) a través de un modelo de votación que designaba al estratega, orador, los comisionados del gran sello, del tesoro y a

${ }^{9}$ Incluyendo la religión. Esto ya se recogía en el Humble Petition and Advice (artículo 11) y en el Instrument of Government (artículos 35 a 37).

${ }_{10}$ El Instrument of Government ya preveía la creación de un ejército y una armada. 
los censores (Harrington 1977e, 362-369) de forma aleatoria mediante sorteo.

Como podemos ver el sistema de Harrington difería del propuesto por Winstanley en tres aspectos esenciales: i) la limitación de la propiedad era relativa y no absoluta, ya que permitía un cierto nivel de titularidad sobre la misma; ii) dejaba abierta la puerta a una monarquía popular, si bien mostraba su preferencia por la República; iii) Harrington limitaba netamente la influencia del hecho religioso sobre la forma de gobierno, desligándolo y estableciendo un fenómeno político autónomo con una mayor identificación entre religión y Estado. Aspectos estos, sobre los que a su vez, bascularán las principales diferencias con Babeuf, como veremos a continuación.

\section{III.EL RESURGIMIENTO DE LA SOBERANÍA POPULAR. MORELLY, CATASTRO, ACCIÓN POLÍTICA Y EL TRIBUNO DE LA PLEBE (MANGOURIT 1788, 13-14) ${ }^{11}$}

Las posiciones utópicas en Francia se plantearon desde una perspectiva más cercana a la concepción natural y alejada de los designios divinos. Ese distanciamiento del ideario que predominaba en Inglaterra resulta explicable en parte por cuanto la Francia del siglo XVIII, Ilustrada y agnóstica, abandonó la religión como origen y explicación de los acontecimientos, pugnando por establecer un pensamiento racional y cartesiano (Aston 2000, 93) $)^{12}$.

Despojado de sus aspectos cosmogónicos, el sistema utópico en Francia presentó aun así sorprendentes paralelismos con los sistemas de gobierno planteados durante el siglo XVII. La obra de Harrington no resultaba desconocida en el París revolucionario (Hammersley 2005, 3-4) ya que en 1792 se presentó ante la Convención Nacional un proyecto de Constitución anónimo -aunque su autor era Theodore Lesueur (Lesuer 1792, 1) ${ }^{13}$ - que apostaba por un modelo constitucional basado en las ideas del filósofo inglés, aunque incluso antes del citado proyecto, sus ideas ya habían calado en los antecesores de los revolucionarios (Monnier y Colin 2016, 4-6).

${ }^{11}$ Una de las primeras referencias al Tribuno de la Plebe se contienen en el panfleto Le Tribun du Peuple au Peuple escrito por André Mangourit. El citado panfleto ridiculizaba la figura de la corona y la nación a las que acusaba de malgastar los bienes de la nación y de nacionalizar la deuda y engañar a los franceses, haciéndoles creer que la resistencia a los nuevos movimiento revolucionarias era una lucha por la libertad

12 Aunque en general, se reconocía la labor de los párrocos rurales o bon curé, lo cierto es que la Iglesia como institución era considerada como una parte más de la monarquía.

${ }^{13}$ Incluía el otorgamiento de la titularidad de la tierra a la Nación divididas por lotes. 
El pensador francés afirmó que la avaricia y la moral decreciente de la época habían convertido en impracticables las leyes de la naturaleza (Morelly 1841, 63-64). Esa vulgaridad moral era el origen de una sociedad dividida entre ricos y pobres que compartían una dependencia mutua en el marco social. La evidente desigualdad convertía en ilógico que se obligase a los hombres - que no se hallaban en la misma situación- a compartir un destino común (Morelly 1841, 70-71). La ley según Morelly debe asegurar -no la propiedad- sino el uso común de todos los bienes por la sociedad (Morelly $1841,86)$ ya que el reparto de los bienes de forma igual o desigual es la causa de todos los vicios y la violencia del ser humano ya que la diferencia entre lo mío y lo ajeno es causa de discordia y por lo tanto debe ser eliminada (Morelly 1841, 117).

Consideró que la libertad política es hacer todo lo que los apetitos del hombre le exigían sin temor ni obstáculos (Morelly 1841, 96-97), aunque tal libertad no pueda ejercitarse en régimen de absoluta independencia, lo cual para este autor significaba el abandono sino en sociedad. Y ese ejercicio en sociedad impide la existencia de amos o esclavos porque la dependencia es recíproca, existiendo únicamente una sociedad estimada como un ente paternal, regida como una familia en el que la propiedad no existía (Morelly 1841, 82-83).

Del bosquejo de dichas ideas, dibujó Babeuf su ideario político, el cual tuvo que desarrollarse -en sus aspectos más prácticos- en unas circunstancias ciertamente complicadas. Militante inicial y teórico del jacobinismo, se apartó de él y criticó duramente a Robespierre por entender que había implantado una dictadura similar a la monárquica negando el derecho de decisión al mismo pueblo (Chalmin 2011, 841-843) ${ }^{14}$ que le había aupado al poder y apartándose radicalmente de su visión dirigida a limitar -que no suprimir- la propiedad. Babeuf sí apostaba por su prohibición, obligando a que los bienes fueran comunes, anticipándose -como fácil es advertir-a los postulados comunistas del siglo siguiente (Marx 2008b, 62) (Engels 1980, 7) $)^{15}$.

Esta lucha le hizo popular -sobre todo tras la caída del antiguo club Bretón- pero no le otorgó excesivas simpatías ni apoyos. La caída en 1794 del

${ }^{14}$ Llegó a escribir un panfleto en 1794 llamado Du systeme de dépopulation en el que de forma pormenorizada describía los abusos y la crueldad de los medios de represión impuestos por el Comité de Salud Pública en Vendée y en el que Babeuf expresaba públicamente sus dudas sobre la validez del recurso a la violencia como medio para lograr los fines.

${ }^{15}$ Marx consideraba que la propiedad común ya había existido en tiempo de los romanos y los celtas. En este punto coincidía con Engels que también atribuía a las antiguas formas tribales de producción una titularidad comunal de los bienes. 
régimen jacobino con la ejecución de sus principales líderes y el amargo sabor que había dejado su herencia, no predisponían al pueblo francés para nuevas aventuras utópicas ni para más pretensiones de igualdad absoluta. Prueba de ello fue la Constitución de 1795 en la que pacíficamente y con escasa oposición se retornó al sufragio censitario y a una cómoda desigualdad que ya había inspirado el texto constitucional de 1791, por lo que más allá de las proclamas lanzadas a través del Tribuno de la Plebe que era su diario de cabecera, se encontró encajonado entre el carisma de Robespierre que le impidió destacar como líder jacobino y el alejamiento de la luchas por los ideales que habían inspirado la Revolución en 1787.

Aunque no era estrictamente hablando -al igual que Harrington- el ideólogo del movimiento utópico, Babeuf sí fue el primero que puso los medios para llevarlo a la práctica. Consideraba que la quiebra del sistema social debido al conflicto sobre la propiedad y la negativa a otorgar la libertad absoluta- había auspiciado la ruptura de la comunidad y la creación de desigualdades, las cuales no habían sido corregidas por los legisladores.

Exigió una devolución íntegra de los derechos al pueblo a través del derecho a la insurrección, so pena de perder su libertad (Babeuf 1969a, 65). Esa insurrección debía realizarse de forma inmediata al ser los medios en ese momento del pueblo, inferiores a los que existían en 1789 tras negar el gobierno de la Convención las libertades recogidas en la Declaración de Derechos, razón por la cual merecían la muerte (Babeuf 1969a, 67-68). Pese a ello, afirmó que la insurrección exigía un intento pacífico articulándose a través de la ley como deseo general del pueblo previa consulta a éste de cuál era su voluntad, siendo la misma votada por la asamblea (Babeuf 1969a, 69), dotando así a la insurrección de la legitimidad necesaria, recurriendo a la violencia cuando no quedare más remedio.

Tal fortalecimiento de los derechos de decisión del pueblo, le sirven para argumentar a su vez la severa crítica que lanza a todos los actores del proceso revolucionario. Denostó la sumisión que los jacobinos aportaron por entender que esa supeditación a las leyes propia del jacobinismo era una suerte de tiranía que debía ser derribada (Babeuf 1969a, 26-28). El régimen de Robespierre, según Babeuf, atentaba (Babeuf 1969a, 32-36) contra las libertades del pueblo, puesto que su gobierno revolucionario era el talismán que «cubría todos los abusos no permitidos». Acusó al abogado de Arras de actuar tiránicamente (Babeuf 1969a, 35), lo que en vida de aquél, oscureció su figura en relación con su némesis.

Despreció la monarquía de uno o varios porque se trataba de un sistema que caía necesariamente en lo más impuro y pérfido, porque el que bebía de la copa de la autoridad sin límites se convertía necesariamente en un tirano. Criticó a los sucesores de los girondinos a los que acusaba de tratar de crear un frente contra la Constitución a la que tildaban de «esqueleto informe» 
(Babeuf 1969a, 50-52). Simplificó el proceso revolucionario en una lucha entre ricos y pobres (Antonelle 1788, 5-6) ${ }^{16}$ y patricios y plebeyos con un carácter perpetuo, en la que la plebe reunía todas las virtudes y los patricios eran los autores de los crímenes (Babeuf 1969, 90-93) (a).

Tras caer Robespierre, culpó a la Convención que debatió la Constitución de 1795 de fomentar la esclavitud del pueblo y en concreto, al padre de dicha Constitución -Boissy D'Anglas- por estimar que el texto que había propuesto como base para la norma suprema de 1795 no era la constitución francesa (Babeuf 1969a, 135-137) al ser la misma aprobada mayoritariamente por realistas. Los realistas no respetaron el bien común y además atentaban contra la mayoría de la población que seguía siendo valedora de la constitución de 1793 (Babeuf 1969a, 143-144), pese a que dicho texto constitucional había sido dejado en suspenso por decisión del gobierno revolucionario (Babeuf 1969a, 174-185).

Abogaba igualmente por examinar las bases del gobierno (Babeuf 1969a, 159-161) afirmando que debía mediar una guerra entre los escribanos y el poder legislativo con el fin de defender la libertad, ya que la promulgación de la verdad está teñida de peligros aunque ofrece grandes bienes. Tal verdad debía asegurarse por medio de las instituciones plebeyas que tienen obligación de asegurar el bien común puesto que la igualdad perfecta responde al pacto primitivo y el pacto social debe otorgar a cada hombre la garantía de que el derecho natural nunca será violentado (Babeuf 1969a, 179). La igualdad de hecho no es por tanto una quimera (Babeuf 1969a, 190).

Esa conclusión le lleva a despreciar la diferencia entre propietarios y no propietarios porque la libertad de propiedad no implica dejar el derecho al arbitrio del propietario sino limitarlo ya que la utilidad de todos permite ese derecho de la propiedad pero exige que sea restringido puesto que el pobre y el rico cuentan con una igualdad común a ojos de la ley (Babeuf 1969a, 194195). La propiedad es un derecho ilegítimo para Babeuf y coincidiendo con Antonelle (Antonelle 1788, 18-19), uno de los derechos más deplorables y errores más graves de la creación humana, siendo la propiedad conjunta el único derecho digno y justo y el único conforme a los derechos y designios de la naturaleza (Babeuf 1969a, 236-238).

Renegó de la connotación negativa del término anarquista en tanto que esa afirmación solo demostraba la incoherencia de los antirrevolucionarios ya que la desorganización se produce en aquella sociedad en la que una parte mínima que identificaba con la nobleza pretendía reducir a la insignificancia a la mayor parte del pueblo (Babeuf 1969a, 219-221).

${ }^{16}$ En lo que coincide parcialmente con Antonelle que consideraba a las clases nobles injustas y crueles. 
Babeuf no era un político, sino un hombre de acción (Buonarroti 1869, 29 ) en su lenguaje y sus hechos, aunque hasta 1794 postulaba que esa acción tuviera acomodo dentro del sistema (Harkins 1990-1991, 434).

\section{IV.HOMBRES DEL REINO. REPÚBLICA DE HOMBRES}

Harrington y Babeuf alcanzan coordenados ideológicas parecidas pero su camino al ecuador discurre por senderos diferenciados.

El pensador inglés rechazaba la monarquía al sustentarse sobre la usurpación de los bienes de la tierra a los demás hombres (Webb 2003, 583), obligándoles a comprar y vender los frutos y cuando esto no era suficiente a apropiárselos por la espada (Winstanley 1941b, 531). Era un poder opresor que esclavizaba a los hijas e hijas del hombre para ser sus sirvientes y que utilizaba los diezmos para pagar a sus ministros y oficiales (Winstanley 1941b, 532). Por tanto, tanto él como su antecedente inmediato Winstanley, inician su pensamiento en una fórmula enraizada en la religión. La fe en Dios permite asentar los principios divinos yuxtaponiéndolos a una estructura de estado en la que prima la voluntad del hombre y su cohesión como comunidad.

Pero en este punto disienten igualmente: Winstanley identifica religión con comunidad mientras que Harrington la vincula al Estado. No era algo nuevo ya que la identidad como Iglesia de Estado se producía desde la época de Enrique VIII, pero la caída de Carlos I y el empuje del puritanismo en la sociedad inglesa de mediados del siglo XVII potencian esa relación aunque convirtiendo la Iglesia de Estado primigenia en religión de estado, obviando la institución eclesial.

La supresión de la monarquía trae aparejada la caída de la fe anglicana como religión predominante y sustituida por la fe del pueblo que conforma la commonwealth. El Protectorado invadió la esfera particular del sujeto, ya que predetermina su forma de comportamiento -limita las actitudes que estima licenciosas- y persigue furibundamente a los papistas pero además, refuerza los vínculos de la comunidad como fuente de bienestar y poder. La idea de felicidad o bienestar común alcanza a todos los ámbitos de la vida del sujeto pero a su vez le supervisa y controla a través del poder que ejercer.

El aspecto religioso es un extremo ausente en el pensamiento de Babeuf. No es un elemento de su política porque no existe la mímesis entre iglesia y estado que se producía en Inglaterra y por la influencia que el pensamiento ilustrado tenía en la sociedad francesa de mediados del siglo XVIII que muto el centro de la sociedad de Dios al hombre. Pero es una explicación en exceso simplista. La religión desaparece del pensamiento galo de la época por la condición de propietaria de la Iglesia y la identidad que tenía con el poder de la Corona. Su identificación como tenedor de bienes le sitúa fuera del 
espectro de pueblo. Es algo más que una mera cuestión de fe o ateísmo. Es su inclusión dentro del esquema que la ubica como cooperadora necesaria de todos los males.

Tales puntos de partida en el pensamiento de ambos pensadores condicionan la posterior evolución de su esquema político, pero no lo oscurecen. Con pensamiento religioso o sin él, Harrington y Babeuf priman al estado por encima de cualquier otro elemento que lo integre. El estado es ley. Y la ley es estado. Pero para que la ley se identifique por el estado debe ser realizada por los miembros de éste, aunque en el caso del pensador inglés no es una democracia pura, sino una forma de gobierno mixta (Gabrielli 2009, 479). En todo caso, ambos exigen la participación del pueblo y no solo de sus dirigentes, pero para alcanzar dicho fin optan por caminos diferenciados.

Harrington estima el poder no puede ser dividido y esa ausencia de división le obliga a controlar su raíz que es la propiedad (Toth 1975, 330-331). Y lo hace construyendo una suerte de aristocracia civil (Pocock 1978, 24-25) que guardaba semejanza con Israel. Una república cuyo legislador era Dios (Pocock 1978, 28), pero que en la Inglaterra del siglo XVII se torna como una auto contemplación del hombre en su estado natural que se realiza a través de una sociedad fundada en la propiedad casi feudal (Pocock 1978, 2429). Harrington infravalora el poder de la nobleza en la Inglaterra republicana, la cual no conseguirá superar la pujante posición de la gentry (Pocock 1978, 31-32) del Protectorado hasta que retorne la monarquía, una vez fallecido Cromwell.

La cuasi equiparación entre el hombre y Dios hace que apueste por una relación de igualdad entre ambos como una suerte de designación y aceptación acordada por su pueblo (Beiner 2014, 176). La religión por tanto, es electiva ya que el pueblo consiente en la misma y no puede ser impuesta por el monarca. Inglaterra es Israel porque elige a su Dios. Evoluciona Harrington de la perspectiva medieval en la que el monarca «elegía» a sus nobles y a sus obispos (Attenborough 1922, 25) y formaba su círculo de confianza a una posición -acorde al signo de sus tiempos- en la que el pueblo consiente al monarca y participa no solo del hecho político sino también del religioso, en contraposición a las ideas hobbesianas que el propio Harrington atacó en el Preámbulo de Oceana (Lovett 2012, 60). Esa evolución, ya anticipada por Winstanley exigía convertir las vetustas estructuras normandas en un nuevo orden en el que las propiedades se repartieran y con ellas, el poder que atesoraban (Arienzo 2018, 102-103).

Tal paralelismo con la nación hebrea le permite justificar la (limitada) tolerancia religiosa, la cual es para él signo inequívoco de las repúblicas, afirmando que la muerte de Cristo se debió exclusivamente a un abuso de poder (Beiner 2014, 182-183). Identidad a la que añade el carácter revocable del covenant alcanzado con Dios y que se funda en el consentimiento popular 
(Beiner 2014, 185), la supremacía de Moisés como un Solón o un Licurgo que dirige al pueblo (Cromwell), la existencia de un Sanedrín que cogobernaba con Moisés, el sometimiento de los sumos sacerdotes -Aarón-al Sanedrín, la rotación en los cargos y la aceptación de la ley por los ciudadanos, así como su participación en la composición de las mismas, que es realmente el ámbito de libertad al que aspira Harrington para el ciudadano inglés (Arienzo $2018,108)$. Pretende eludir la forma de gobierno absoluta -propia del Imperio Otomano- a través de la distribución de la propiedad, que reparte no solo el poder, sino que le otorga estabilidad (Lovett 2012, 66-67).

Se trata de una composición política elaborada. Acepta el origen divino de la república pero supeditado al pacto con el pueblo que ha elegido a Dios y rechaza el excesivo poder de la curia eclesial. Exige una conciencia de estado, dirigida por éste y sin participación de instituciones exógenas a su estructura, aunque aquéllas cuenten con una evidente prédica en la materia. Curiosamente, entiende que también concurre esa similitud con Israel pese a que las Escrituras - Antiguo Testamento- consideran que el pueblo judío era precisamente el elegido por Dios Pero hábilmente muta esa idea en una más acorde a sus propósitos.

La elección del poder en Morelly y Babeuf se ofrece desde una perspectiva popular, similar a la que postula Harrington, aunque la ausencia de la religión hace que carezca de un nexo de unión más allá de la mera condición de hombre. Esa ausencia del hecho religioso, magnifica y amplia el alcance de esa asamblea popular que postula Babeuf. Y lo hace sin cortapisas, puesto que la pertenencia al puritanismo imperante en Inglaterra es sustituido por la pertenencia a la condición natural de hombre, reconociéndole la capacidad para actuar y decidir y una capacidad de decisión que se optimiza al máximo, le aleja del jacobinismo más pragmático y menos idealista y le sirve además como objetivo a cumplir con sus pretensiones (Roza 2011a, 86-87).

El ideario del Tribuno de la Plebe se apoya en la condición del hombre y sus derechos inmutables para aspirar a una sociedad comunitaria (Roza 2011a, 90-92) que partía del derecho natural, considerado como derecho de vida y que huía de aspectos religiosos. No era una vida miserable, sino una vida en la que se contaran con los goces mínimos e indispensables a la que une la exigencia de una observancia estricta de la misma y aplica - una vez caído el jacobinismo- un plan de acción que culminará con la fallida Revolución de los Iguales (Roza 2011a, 99). No deja de ser una forma de que el hombre se apropie de su destino, individual y colectivo (Roza 2011a, 116).

Fácil es advertir la confluencia de ambos pensadores en el hecho esencial que es la participación el conjunto del pueblo en la política. Pero el reflejo que emite el pensamiento harringtoniano que observa una república excluyente por el hecho religioso, se torna en una república excluyente por la condición de propietario estricto. Se establece una composición asimétrica entre 
ambas repúblicas en la que se delimita la participación atendiendo a un parámetro que radica en la base de la teoría política que postulan y que son la religión y la propiedad.

Partiendo de dicho aspecto, el régimen de participación se maximiza dentro de tales límites, apostando Babeuf por una libertad plena carentes de obstáculos y Harrington por una intervención del sujeto en la política de forma absoluta a través de los diversos medios que postula la República de Oceana. Se trata de una moneda de dos caras: la república religiosa y parlamentaria inglesa y la república popular tardo- revolucionaria francesa. En ambas anida un quebranto con el sistema preexistente y una derivación hacia posiciones en las que prima el sujeto por encima de cualesquiera otras consideraciones.

\section{PROPIEDAD: ESCLAVITUD Y PODER}

La segunda línea de pensamiento común que mantienen Harrington y Babeuf radica en el concepto de propiedad. Atacan su fundamento pero sin embargo, la conclusión que alcanzan en relación a la misma resulta netamente antagónica. Para Harrington, la propiedad es mal, pero también poder. Para Babeuf, la propiedad es mal y solo genera esclavitud. Surge obviamente la cuestión de a qué obedece esa ramificación entre ambos. En Oceana se había definido la distribución de la tierra como una distribución entre el pueblo (Beiner 2014, 179-181) conforme a los designios divinos siendo también mimética con el reino de Israel en la que existía una ley agraria que otorgaba esa propiedad (Beiner 2014, 185).

Curiosamente esa conceptuación de la propiedad permite que Harrington sea aceptado como el creador de los parámetros de la monarquía constitucional (Pettit 2012, 49) al fijar la participación de los propietarios en dicho sistema (Capozzi 1998, 198). Trataba de establecer un sistema un tanto complejo de equilibrio de fuerzas a nivel institucional y social (Capozzi 1998, 202). Entendía que la ley en la República era algo más que la expresión del Estado por cuanto debía proteger la libertad del individuo, ya que sin él no hay estado (Arienzo 2018, 108). Pero esa libertad, teniendo en cuenta el carácter corruptible del hombre, exige que se le dote de la antigua prudencia y una estructura de instituciones que prevea dicha situación y que ofrezca regularidad política (Arienzo 2018, 109). Ello no impide que él mismo y Winstanley consideren que el pueblo es corruptible. Las leyes, por decirlo de alguna forma, le protegen de sí mismo, visión que provenía de su pertenencia a la más estricta rama del protestantismo que aceptaba la predestinación (Bowman 2005, 406).

La propiedad es un don que Dios entregaba al hombre, que a su vez lo pagaba con un trabajo industrioso (Polin 1952, 28-29), apartándose de la idea 
lockiana de propiedad que la concebía como una entrega de Dios que podía ser objeto de transmisión. La propiedad es una forma de atribución imperfecta que derivaba del uso más o menos útil que el hombre realizase de la misma y que podía dar lugar a una incorrecta distribución. La ley agraria es por tanto necesaria para que se produzca una distribución y un reparto justo (Polin 1952, 29-30). Y esa distribución cuenta con una vertiente política ya que el gobierno no es sino la forma de constituir un estado civil alrededor de un interés común que puede ser el gobierno de las leyes o la prudencia de los ancianos.

Esto permite que Harrington -a través de la distribución de la propiedadenuncie la forma de gobierno en términos de proporción: un solo propietario es monarca, pocos propietarios son nobleza, muchos propietarios son un gobierno popular (Polin 1952, 31-33). La ausencia de proporcionalidad causa conflictos por la tenencia de la propiedad y corrompe al gobierno. La ley agraria en resumen, elimina la desigualdad y fomenta el trabajo. No solo eso. Considera que si la propiedad se encuentra bien repartida, los errores del pueblo corresponden a los que les gobiernan. No es una afirmación marxista, pero casi (Polin 1952, 41).

La distribución de la propiedad permite a su vez, evitar la concentración de poder. Propiedad y poder se solapan nuevamente (Lovett 2012, 59-60). A la imagen y usanza romana -que logró la plena libertad-cuando expulsó a los monarcas tarquinios, entiende que la República de Oceana debe basarse en el imperio de la ley y la ausencia de tiranos (Lovett 2012, 63), ofreciendo una nueva clase política -que había logrado auge y pujanza bajo Enrique VIII- la gentry que debía ser quien ocupase el poder (Bowman 2005, 400401 ), siguiendo un estricto sistema de rotación que a su vez, estaría supervisado por órganos específicos (overseers ${ }^{17}$, constables y churchwardens) (Winstanley 1941b, 546-547).

En resumen: no abandona el vetusto concepto inglés de que la propiedad es la base del poder. La idea sustanciada de que solo los propietarios gobiernan el país. Pero sin denostarla, sí afirma que su tenencia por un solo hombre o unos pocos es negativa y por tanto, su reparto equivale a un reparto de poder político. El hombre necesita la propiedad en su justa y estricta medida y no puede superar unos parámetros concretos, como evidencian las leyes que postula en Oceana para sustentar su afirmación (que incluían, entre otros, una renta máxima y herencia con un límite de percepción).

La demonización de la propiedad es un elemento común en Babeuf. Pero en el revolucionario francés bascula hacia un enfrentamiento y destrucción del hecho propietario. Babeuf asume la idea de Harrington de que la

${ }^{17}$ Figura propia del pensamiento digger que lo conceptuaba como guardián de la paz y la ley. 
propiedad es causa de conflicto. Pero no es suficiente compartirla. Hay que destruirla. Abolirla. Eliminarla de la sociedad. No es suficiente con limitarla.

Su obsesión radicaba en acabar con el expolio perpetuo que sufrían los plebeyos, expropiados por una casta de acaparadores, tiñendo dicha circunstancia de negativos y derivados de un constante agravio (Roza 2016c, 192-194). No oculta que supedita el hecho político al hecho social (Mazauric 1992, 513). Debe imperar el bien común, extirpar la miseria y convertir en prioridad el derecho a la existencia por encima de cualquier otro bien social (Mazauric 1992, 514). Otorga a la vida y a la persona el carácter de propiedad suprema, añadiendo que el trabajo debe remunerarse de forma permita que el hombre pueda adquirir los medios necesarios para asegurar la subsistencia (Mazauric 1992, 516) y contribuir a las cargas del Estado, considerando que Francia era una única comunidad a efectos fiscales y que las cargas debían ser comunes, aunque estuvieran mal repartidas (Babeuf 1789b, 154- 155). Los impuestos según debían ser de carácter personal y real. El primero gravaba los ingresos del hombre, siendo el precio que se pagaba por la seguridad que el estado otorgaba al ejercicio de su industria habitual y el segundo los bienes, siendo el precio que pagaba el hombre al estado por la protección de los medios necesarios para su subsistencia, fijándose ambos de forma proporcional (Babeuf 1789b, 5-6; 124-125).

La propiedad forma parte de los atributos del hombre, pero dirigida en todo caso a su subsistencia y no como un medio para alcanzar el poder político. Se advierte aquí además la evolución de Babeuf: del teórico que era hasta 1793, al defensor de la ley agraria posterior y comunista pleno a partir de 1795 (Roza 2011a, 9). Consideraba que el reparto de la tierra permitía defender los derechos de los señores pero olvidaba frecuentemente al feudatario. Había por tanto que igualar sus derechos, ya que a ambos les liga la tierra pero el feudatario que la labra, cuida y se ocupa de ella, carece de derechos sobre la misma, mientras que el señor que exhibe sus derechos de familia, apenas la cuida (Pelletier 1965, 47-48). La experiencia personal de Babeuf en Picardía durante la que pudo examinar los registros y cartas de propiedad de los señoríos sobre la tierra- le convencieron de los abusos que sufría el campesinado y el modo -claramente improductivo- en el que se repartían las mismas. Esto le llevo a la certeza de que era necesario reformar el sistema y entregar la plena capacidad productiva a la colectividad (Pelletier 1965, 62-64).

La ausencia de logros en ese sentido, hace que se encuentre francamente decepcionado con la Revolución (Chalmin 2015, 840-841). La lucha social en la que se había embarcado no se ha logrado ni tan siquiera se ha acercado a sus objetivos esenciales. Ejecutados los principales líderes jacobinos, la Constitución de 1795 suponía un retroceso en los derechos alcanzados en el texto de 1793, ya que implicaba el retorno del sufragio censitario. A los postulados de Boissy D'Anglas quien calificaba la igualdad absoluta como quimera (Chalmin 2015, 843) reaccionó con dureza calificando esa constitución 
como un «código negro» a la usanza del trato que confieren los colonos a sus esclavos. Esa persecución del derecho de propiedad es ratificada por su compañero de fatigas, Buonarroti, quien señaló que «la libertad y la igualdad no recibirían una aplicación útil y duradera sin la reforma del orden de la propiedad» (Buonarroti 1869, 50-51), convirtiendo los bienes comunes en el más alto objetivo perteneciendo los frutos y que los frutos de la tierra eran de todos los hombres (Buonarroti 1869, 70-71).

La propiedad como enemiga del hombre se contrapone a la libertad y a la igualdad, exigiendo que el pacto social reparase las injusticias. Estas injusticias puede ser origen de la ley natural al establecer desigualdades entre los hombres, dotándoles de atributos naturales distintos (Babeuf 1789b, XXVXXVI) y no heredados de épocas precedentes (como l'heritage de francs, derechos señoriales de origen feudal muy lesivos para los arrendatarios que vinculaban al arrendatario o al dueño a una prestación personalísima de trabajo con su señor) (Babeuf 1789b, 11-12).

La aplicación práctica de estos principios supuso la inclusión en el Acta de Insurrección con el que comenzó la Conjura de los Iguales de medidas tales como el alzamiento, la toma de armas y la destrucción del gobierno tiránico, puesto que la incorrecta distribución de los bienes era causa de la desigualdad y de los problemas de la nación (Buonarroti 1869, 94-104). Por otro lado, la ausencia de propiedad permite que Babeuf derribe la figura monárquica, ya en un espacio de propiedad común, dicha propiedad no puede ser asignada por un solo hombre - el rey- que deviene innecesario. Entronca con Morelly, quien ya había denostado la monarquía y apostado por la república, sistema éste en el que el interés personal quedaba supeditado a una igualdad de fortuna y condición que equilibraba el interés común de la sociedad (Morelly 1841, 102-103), añadiendo que la democracia es la forma de gobierno en la que los hombres únicamente acuerdan obedecer las leyes de la naturaleza a través de la familia, tribu, ciudad y provincia (Morelly 1841, 152-153) bajo la dirección de sus padres de familia (Morelly 1841, 105) y el soberano en esa situación únicamente tiene que ponerse al frente de la misma, rigiéndose por las leyes naturales previstas, no pudiendo apartarse de las mismas (Morelly 1841, 108-109).

Esa distribución anticipada por Morelly obedecía al derecho de usufructo -que no propiedad- que atribuía al hombre, conforme a esa distribución social (Morelly 1841, 155-156), hombre que por otro lado, rechazaba el lujo y los artículos suntuosos (Morelly 1841, 161-162).

\section{VI.CONCLUSIONES}

Harrington y Babeuf no dejan de ser dos caras de la misma moneda. Pero esa moneda no representa lo mismo. El pensamiento de Harrington es un 
pensamiento -que dentro de sus limitaciones- se encuentra enmarcado en el liberalismo inglés de mediados del siglo XVII y, aunque bastardo en parte de sus planteamientos, está fuertemente vinculado al concepto de propiedad como fuente de poder.

No obstante, el liberalismo de Harrington depende en gran medida de la evolución religiosa que imperaba en la Inglaterra de mediados del siglo XVII y que culminó la Reforma que la había precedido en los años anteriores. Es una cuestión que no deja de resultar llamativa ya que de no haber sido así, la propuesta de Harrington habría anticipado en más de cien años, los principios básicos de la Revolución Francesa, al establecer un sistema político republicano, aconfesional y precursor de los derechos del hombre.

Pese a ello, la estructura social de Harrington -aun avanzada- no logra superar la trinchera del ecumenismo anglicano que -aun con cierta tolerancia- propugnaba la primacía del puritanismo apoyada en las tesis más extremas del calvinismo europeo. Transformaba la Iglesia de Inglaterra, atacándola y reconstruyéndola dotando de prevalencia a la organización política que era la propia comunidad evangélica a la que pertenecía el sujeto y desde cuyas estructuras sociales se erigía el nuevo estado inglés.

Esos cimientos debían soportar una estructura en un equilibrio complicado porque suponía en la práctica suprimir la figura de la realeza así como la alta nobleza, aparte de subyugar a la propia institución eclesiástica. Es decir, invertir la disposición social existente, y dotar a las comunidades religiosas de una autonomía casi plena alejadas de la rígida identificación entre Iglesia, Corona y Estado que había sentado Enrique VIII y que había sido mantenida por Isabel I.

La edificación auspiciada por Harrington agrietó igualmente el principio básico en el que se asentaba el ordenamiento inglés. Su ataque a la propiedad como pilar del sistema ponía en duda la relevancia de la misma como medio para sustentar la capacidad política de sujeto. Harrington relativiza la propiedad y la pone al servicio de la sociedad para desvincularla del concepto de poder y fijarla como medio de subsistencia. La acepta pero declina su influencia. La difumina en el conjunto de la sociedad. Pero no se atreve a destruirla.

El mantenimiento de estos principios evidencia el abandono que efectúa Babeuf respecto de los postulados del pensador británico para establecer su propio criterio pero sin desligarse totalmente del -por aquel entonces- original y reaccionario planteamiento del erudito inglés. Babeuf obvia el hecho religioso. Su concepción del hombre como ente pleno de derechos le impide aceptar el deísmo aun de forma implícita. El hombre es un ciudadano al que no se le pueden poner trabas. Lo considera en términos mayestáticos y esa condición implica que debe rechazar la idea de un ser superior al que deba rendir pleitesía. 
La renuencia al fenómeno divino hace que igualmente pueda aceptar y proclamar el carácter innecesario de la monarquía. Si el rey tenía un origen divino en el siglo XVII, en la centuria siguiente no es más que un hombre que cuenta con unos vetustos e injustos derechos sobre sus súbditos. Si a ello se le une el que carece de un inmediato valedor por cuanto no se acepta la influencia de Dios, el monarca no es mejor que los demás hombres y por lo tanto, deviene superfluo.

Aquí convergen ambos. Un republicanismo militante en el que la importancia del hombre y de la comunidad se eleva sobre el yo, aunque ese yo sea reconocido como elemento clave en la nueva construcción social. Pero esa república -obviando el fenómeno religioso- es más compleja en Harrington que en Babeuf. La mentalidad del pensador no le permite concebir una sociedad plana en la que únicamente resida un colectivo. Crea una pirámide social aunque sea a meros efectos de control. Pero esa pirámide -plena de reminiscencias del esquema que tenía la Inglaterra medieval- no deja de exponer la necesidad que advierte en crear un espacio en el que se celebre y se discutan las cuestiones esenciales del colectivo, sometida a una rígida supervisión.

Esa supervisión es inexistente en Babeuf. El motivo de tal carencia es la confianza que tiene en el sujeto que a su vez es desconfianza en Harrington. El hombre es corruptible. Debe ser controlado. Babeuf aspira a confiar en él. Pero no es una fe ciega. No le queda más remedio ya que si no cree en él, mina su confianza en la colectividad y habilitaría los mecanismos necesarios para sujetarlo y enjuiciarlo. Se establecería nuevamente un sistema en el que el hombre se halla supeditado a un tercero que podría ser un rey, un monarca, un principio o un tirano. Y Babeuf no acepta sino un yo puro, estricto y autocomplaciente.

Por tanto, las repúblicas utópicas de Babeuf y Harrington se separan por su propia concepción del hombre y la resignación que debe mostrar ante la figura del poder. Harrington la acepta aunque sea de forma parcial, pero Babeuf no está dispuesto a ello. Y esas limitaciones que separan a uno y a otro, implican necesariamente que la sociedad que arrojen resulte diametralmente distinta, colocando al hombre en situaciones netamente diferentes: libre con limitaciones para Harrington puesto que es observado por el poder y la religión; libre de forma absoluta para Babeuf ya que no existen trabas a su comportamiento.

Tales argumentos son los que a su vez permiten distinguir a ambos pensadores a la hora de abordar la problemática de la propiedad. Lo hacen desde una perspectiva claramente negativa en todo caso. Para Harrington la propiedad es mal necesario pero que puede ser reconvertido en un elemento que facilite la coexistencia y la cohesión del hombre a través de los bienes comunes y su puesta a disposición en favor de la comunidad. Otorga un pequeño espacio a la propiedad privada entendida como el producto de un artesano o 
un industrial eficiente o como medio para recibir -con límites- las herencias del hombre.

Esta idea permite desvincular poder y propiedad. La propiedad que era signo y símbolo del poder real y de la influencia de la alta nobleza inglesa: el rey como dueño supremo de la tierra entregaba la misma al noble y éste otorgaba vasallaje, desaparece íntegramente. Las manor courts -jurisdicciones privadas que la Corona entregaba a la nobleza- quedarían abolidas y su destrucción, y la creación de un nuevo sistema judicial apartado de la figura de la propiedad, separa el poder y su ejercicio del fenómeno de la distribución de la tierra.

Sin embargo, Harrington no logra avanzar hasta el siguiente estadio. Se queda estancado en el espejo en el que se refleja. La condición de trasunto de Oceana respecto del Protectorado cromwelliano hace que no mire más allá. Su devoción a la república no le permite plantearse si ese espejo puede quebrarse o no y acepta un cierto conformismo con sus postulados.

Babeuf por su parte, acepta las tesis de Harrington pero nuevamente da un paso más. Es militante. Es activo. Es luchador. Y es pragmático. Abandona claramente la teorización y apuesta por su ejecución. No obstante, la lucha interna de Babeuf se ciñe en hasta qué punto puede poner en práctica sus ideas. Inicialmente rechaza la violencia, pero en su etapa final no duda en apoyar la insurrección como medio de devolver al hombre lo que estima que son derechos que le corresponden ante la convicción de que todos los demás medios han fracasado. Y el motivo principal de su lucha es inicialmente los derechos de propiedad para desembocar en la lucha política.

La posición de la propiedad en Francia era más conflictiva que en Inglaterra. Los derechos feudales, bastante más agresivos que en las islas, ocasionaban además una distribución irregular de las cargas del país hacía la bancarrota que había acelerado el proceso revolucionario. Esa situación supuso que se plantease la necesidad de abolir la propiedad. Pero la constitución de 1791 fracasó en ese punto, ligando a su vez el derecho de voto con las rentas y la constitución de 1793 quedó en suspenso por la decisión del gobierno jacobino de centrarse en la lucha contra los enemigos de la revolución. El retorno al sufragio censitario que se plantea en el texto de 1795, hace decidirse finalmente a Babeuf a dar el paso sobre el que siempre fue dubitativo. Y lo acomete con todas las consecuencias.

Babeuf asume lo que Harrington no hizo. Pero dónde Harrington triunfa, a nuestro juicio Babeuf fracasa. No solo en ese momento, sino en la influencia posterior. Es el modelo de Harrington en el que en la actualidad cuenta con una mayor vigencia. Un modelo más equilibrado - exceptuando el hecho religioso- que el propuesto por el pensador francés, aunque éste último gozó de una extraordinaria popularidad tras reconocerle su condición de precursor del comunismo (Marx 1985a, 90-91). 
La realidad es bien distinta. Más allá de la función social que la mayoría de los ordenamientos políticos actuales reconocen a la propiedad, tal reconocimiento no ha impedido que se acepte pacíficamente la propiedad privada, incluso en ordenamientos prototípicamente de ideología comunista, aunque con ciertos matices. Parece que a día de hoy, el pensamiento de Babeuf y Harrington ha encontrado un equilibrio en el mundo contemporáneo que no tuvo en el momento en que fue formulado, si bien, el pensamiento del teórico inglés ha sufrido posteriores reformulaciones puesto que su concepto de propiedad ha sido más que superado en la actualidad. El reconocimiento del sujeto como ser libre, ostentador de derechos, capaz políticamente hablando, exige imperiosamente reconocerle el derecho a formular y administrar su esfera patrimonial como considere conveniente y por tanto, las limitaciones a su patrimonio no tienen cabida, más allá de las limitaciones que puedan tener en torno a la contribución en el sostenimiento de las cargas del Estado. La libertad del hombre que auspiciaba Babeuf y reconocía Harrington, excede del concepto de colectividad y comunidad en el que ambos la insertaban, para aceptar la necesidad de gestionar todos los aspectos, frente a un poder que debe garantizar y responder de los mismos.

Resulta difícil aceptar en nuestros días que -sin perjuicio de las cargas públicas que pueda verse obligado a aceptar por el bien del conjunto de la sociedad-no sea posible gestionar el haber de bienes que el hombre ostenta y administrarlo a su antojo. Pese a ello, advertimos determinadas tendencias que buscan reducir esa capacidad para reconducirla a una estricta aplicación del máximum jacobino o que pretenden que prevalezca una función social de la propiedad respecto al derecho a su tenencia por el sujeto. Se trata de propuestas que buscan implantar medidas notablemente intervencionistas no solo en la esfera pública, sino también en la privada.

¿Se trata realmente de una redistribución de la riqueza o de un nuevo control a la libertad del sujeto? Desde un punto de vista objetivo parece aventurarse más lo segundo, ya que precisamente los estados modernos conceptúan al individuo como un contribuyente neto a las necesidades públicas por lo que el control de su patrimonio es un control a su libertad fundado en la detracción del producto de su trabajo para el sostenimiento de estructuras que pueden exceder lo razonable.

En cualquier caso, parece que esa exigencia rompería el equilibrio existente puesto que en la práctica ata al hombre a una estructura de gobierno determinada y le impide progresar allende de unos límites concretos, quedando sujeto en todo caso, a la decisión del propio estado. Es una limitación a los derechos básicos del hombre que rompe el equilibrio entre poder e individuo, que implica en la práctica que se cercene la libertad del hombre para supeditarla nuevamente al poder. No deja de ser irónico por tanto que ese quebranto que se produciría en la libertad del sujeto si pierde sus atribuciones 
sobre la propiedad, suponga la caída de los postulados de Babeuf y Harrington aunque pueda conllevar la derrota de la propiedad.

Un triunfo agridulce de ambos, en todo caso.

\section{BIBLIOGRAFÍA}

Alsop, J. D. 1994. A High Road to Radicalism? Gerrard Winstanley's Youth. The Seventeenth Century. Tomo 9. N. ${ }^{\circ}$ 1. Durham: 11-24.

Antonelle, Pierre Antoine. 1788. Catechisme du Tiers Etat. Acceso el 12 de agosto de 2020. https://gallica.bnf.fr/ark:/12148/bpt6k47458w.

ArIENzo, Alessandro. 2018. Le libertà in conflitto. Il dibattito inglese da Giacomo I a James Harrington. Scienza \& Politica. Vol. XXX. N. 58: 95-114.

Aston, Nigel. 2000. Religion and Revolution in France. 1780-1804. London: MacMillan Press Ltd. First Published.

Attenborough, Frederick Levi. 1992. The Laws of the Earliest English Kings. London: Cambridge University Press.

BABEUF, Gracchus. 1969a. Le tribun du peuple (1794-1796). Textes choisis et presentés par Armand Saïtta. París: Union Generale D’Éditions.

BABEUf, François Noelle. 1789b. Cadastre perpétuel, ou Démonstration des procédés convenables à la formation de cet important ouvrage. París: Garnery \& Volland. Acceso el 12 de agosto de 2020. https://gallica.bnf.fr/ark:/12148/bpt6k56644q.

BARnARD, T. 1997. The English Republic (1649-1660). New York: Longman Limited.

BeInER, Ronald. 2014. James Harrington on the Hebrew Commonwealth. The Review of Politics. University of Notre Dame. N N$^{\circ} .76: 169-193$.

Bowman, G. 2005. Justice in a World Turned Upside Down: Utopian Visions in the English Civil War and Revolution. Contemporary Justice Review. Vol. 8. No. 4: 397-408.

Buonarroti, Filippo. 1869. Gracchus Babeuf et la conjuration des Égaux. Paris: Armand Le Chevalier Editeur. Acceso el 12 de agosto de 2020. https:/gallica. bnf.fr/ark:/12148/bpt6k6274580m.texteImage.

CAPOZZI, E. 1998. Republicanism and representative democracy: The heritage of James Harrington. European Review of History. Autumn: 197-204.

Chalmin, Ronan, Y. 2015. Éthique et rhétorique de la Révolution chez Gracchus Babeuf et Toussaint Louverture. MLN 130: 836-862.

Engels, Friedrich. 1980. Tesis sobre Feuerbach. Moscú: Editorial Progreso.

FitzGibBons, Jonathan. 2013. Hereditary succession and the Cromwellian Protectorate: the offer of the Crown reconsidered. The English Historical Review. Vol. 128. No. 534: 1095-1128.

Gardiner, Samuel Rawson. 1906. The Constitutional documents of the Puritan Revolution. 1625-1660. Oxford: Oxford at Clarendon Press.

Guizot, F. 1985. Historia de la Revolución de Inglaterra. Madrid: Sarpe. 
Hammersley, Rachel. 2005. The Commonwealth of Oceana de James Harrington: un modèle pour la France révolutionnaire?. Annales historiques de la Révolution française. Les Iles britanniques et la Révolution française. $\mathrm{N}^{\mathrm{o}}$ 342: 3-20.

HARKINS, James. 1990-1991. The socialism of Gracchus Babeuf on the Eve of French Revolution. Science and Society: 427-441.

HARrington, James. 1977a. «The Commonwealth of Oceana.» En Political works of James Harrington. Edited with an introduction by J.G.A. Pocock. Cambridge University Press. Cambridge. First Published: 155-360.

— 1977b. «The Prerogative of Popular Governement.» En Political works of James Harrington. Edited with an introduction by J.G.A. Pocock. Cambridge University Press. Cambridge. First Published: 389-566.

— 1977c. «Pian Piano or Intercourse between H. Ferne, Dr. in Divinity and J. Harrington, Esq, Upon occasion of the Doctor's Censure of the Commonwealth of Oceana.» En Political works of James Harrington. Edited with an introduction by J.G.A. Pocock. Cambridge University Press. Cambridge. First Published: 369-388. 1977d. «The Stumbling- Block of Disobedience and Rebellion.» En Political works of James Harrington. Edited with an introduction by J.G.A. Pocock. Cambridge University Press. Cambridge. First Published: 567-578.

- 1977e. «The Manner and Use of the Ballot.» En Political works of James Harrington. Edited with an introduction by J.G.A. Pocock. Cambridge University Press. Cambridge. First Published: 361-368.

LESUER, Theodore. 1792. Idées sur l'espece du gouvernement populaire qui pourrait convenir a un pays de l'entendue \& de la population presumée de la France. París: Imprimerie Mayer \& St. Martin. Acceso el 12 de agosto de 2020. https:// gallica.bnf.fr/ark:/12148/bpt6k5725628x/f2.

LovetT, Frank. 2012. Harrington's empire of law. Political Studies. Vol. 60: 59-75.

MAILlARD, Alain. 1994. La génération communiste de 1840 et la mémoire de Gracchus Babeuf. L' Homme et la société. Número 111-112: 89-100.

Mangourit, Michel Ange (André). 1788. Le Tribun du Peuple, au Peuple. Paris: 1- 42. Acceso el 12 de agosto de 2020. https://gallica.bnf.fr/ark:/12148/bpt6k47205r.image.

MARX, Karl. 1985a. La critique moralisante et la moral critique. En Sur la revolution française. Écrits de Marx et Engels. Messidor. Editions Sociales. Paris.

2008b. El Capital. Tomo I. Volumen I. Madrid: Siglo XXI Editores.

Mazauric, Claude. 1992. Babeuf et la République. Cahier des Annales de Normandie. Recueil d'études offert à Gabriel Désert. №. 24: 513-524.

McGurk, John. 1999. The Tudor Monarchies. 1485-1603. Cambridge: Cambridge University Press.

Monnier, R. et Colin, A. 2016. Itinéraire d' un traducteur de la révolution à la restauration. Pierre-François Henry. Traducteur de James Harrington. Annales historiques de la Révolution française. Nº. 384: 3-24.

Morelly, Étienne-Gabriel. 1841. Code de la nature ou le veritable esprit de ses lois. Reimpression complete. París: Paul Masgana. Libraire-Editeur.

Moro, T. 1977. Utopía. Barcelona: Clásicos Editoriales Planeta.

Pelletier, Antoine. 1965. Babeuf feudiste. Annales Historiques de la Révolution Française. Jan 1: 29-65. 
PetTit, Philip. 2012. The republic, old and new. Renewal: a Journal of Labour Politics: $47-60$.

Pocock, John Greville Agard. 1978. Contexts for the Study of James Harrington. Il Pensiero Politico. Jan 1. No. 11: 20-35.

PolIN, Raymond. 1952. Économie et politique au XVIIe siècle: 1' « Oceana » de James Harrington. Revue française de science politique. $2^{\mathrm{e}}$ année. $\mathrm{N}^{\mathrm{o}}$. 1: 24-41.

Rogers, M. 1996. Gerrard Winstanley on Crime and Punishment. The Sixteenth Century Journal. Vol. 27. No. 3: 735-747.

Rowland, Christopher. 2014. Gerrard Winstanley: a man for all seasons. Prose Studies. Vol. 36. No. 1: 77-89.

Roza, Stephanie. 2011a. Situation de la connaissance du babouvisme. Cahiers d'histoire. Revue d'histoire critique. $\mathrm{N}^{\mathrm{o}}$. 115: 1-13.

- 2014b. Comment l'utopie est devenue un programme politique: Morelly, Mably, Babeuf, un débat avec Rousseau. Annales historiques de la Révolution française. Octobre-décembre. No. 378: 111-118.

- 2016/1c. Deux conceptions de 1'histoire en révolution: Barnave et Babeuf. Presses Universitaires de France. Actuel Marx. №. 59: 184-199.

SAInT-Just, Louis-Antoine. 1946. Oeuvres de Saint- Just. Discours- Rapports Institutions Républicaines. Organt- Esprit de la Révolution. Proclamations- Lettres. Introduction de Jean Gratien. Éditions de la Cité Universelle. 1946.

Smith, David, L. 1999. Oliver Cromwell. Política y religión en la Revolución Inglesa. 1640-1658. Madrid: Akal. Temas de Historia.

Tотн, K. 1975. Interpretation in Political Theory: The Case of Harrington. Review of Politics. Jul 1. No. 37: 317-339.

WeBB, D. 2003. Contract covenant and class- consciousness: Gerrard Winstanley and the Broken Promises of the English Revolution. History of Political Thought. Vol. 24. No. 4: 577-598.

Winstanley, Gerrard. 1941a. «Truth lifting up its Head above Scandals». En The works of Gerrard Winstanley: with an appendix of documents relating to the Digger movement. Edited with and introduction by George H. Sabine. Cornell University Press. New York: 99-149.

1941b. «The law of freedom in a platform». En The works of Gerrard Winstanley: with an appendix of documents relating to the Digger movement. Edited with and introduction by George H. Sabine. Cornell University Press. New York: 501605.

1941c. «The new law of righteousness». En The works of Gerrard Winstanley: with an appendix of documents relating to the Digger movement. Edited with and introduction by George H. Sabine. Cornell University Press. New York: 149247.

— 1941d. "The true levellers standard advanced.» Incluido en The works of Gerrard Winstanley: with an appendix of documents relating to the Digger movement. Edited with and introduction by George H. Sabine. Cornell University Press. New York: 247-269.

— 1941e. «A new yeers gift for the Parliament and armie.» En The works of Gerrard Winstanley: with an appendix of documents relating to the Digger move- 
ment. Edited with and introduction by George H. Sabine. Cornell University Press. New York: 353-399. 


\title{
DE HOMBRES DEL REINO A REPÚBLICA DE HOMBRES. COLECTIVIZACIÓN, COMUNIDAD Y PODER EN HARRINGTON Y BABEUF
}

\author{
From men of the kingdom to a republic of men. \\ Collectivization, community and power in Harrington and \\ Babeuf
}

\author{
Luis Sánchez Quiñones \\ Abogado \\ luissanchezquinones@hotmail.com
}

http://dx.doi.org/10.18543/ed-68(2)-2020pp293-321

\section{Copyright}

Estudios de Deusto es una revista de acceso abierto, lo que significa que es de libre acceso en su integridad. Se permite su lectura, la búsqueda, descarga, distribución y reutilización legal en cualquier tipo de soporte sólo para fines no comerciales, sin la previa autorización del editor o el autor, siempre que la obra original sea debidamente citada y cualquier cambio en el original esté claramente indicado

Estudios de Deusto is an Open Access journal which means that it is free for full access, reading, search, download, distribution, and lawful reuse in any medium only for non-commercial purposes, without prior permission from the Publisher or the author; provided the original work is properly cited and any changes to the original are clearly indicated. 